\title{
Implications of a RAD54L polymorphism (2290C/T) in human meningiomas as a risk factor and/or a genetic marker Paola E Leone ${ }^{1}$, Marta Mendiola ${ }^{2}$, Javier Alonso ${ }^{2}$, César Paz-y-Miño ${ }^{1}$ and Angel Pestaña*2
}

\author{
Address: ${ }^{1}$ Laboratorio de Genética Molecular y Citogenética Humana, Pontificia Universidad Católica de Ecuador, P.O. Box 17-1-2184, Quito, \\ Ecuador and 2 Unidad de Biología Molecular y Celular del Cáncer. Instituto de Investigaciones Biomédicas "A. Sols", CSIC-UAM, C/ Arturo \\ Duperier 4, 28029 Madrid, Spain \\ Email: Paola E Leone - PLEONE@puce.edu.ec; Marta Mendiola - mmendiola@iib.uam.es; Javier Alonso - fjaviera@iib.uam.es; César Paz-y- \\ Miño - CPAZYMINO@puce.edu.ec; Angel Pestaña* - apestana@iib.uam.es \\ * Corresponding author
}

Published: 4 March 2003

BMC Cancer 2003, 3:6
Received: 31 October 2002

Accepted: 4 March 2003

This article is available from: http://www.biomedcentral.com/147I-2407/3/6

(c) 2003 Leone et al; licensee BioMed Central Ltd. This is an Open Access article: verbatim copying and redistribution of this article are permitted in all media for any purpose, provided this notice is preserved along with the article's original URL.

\begin{abstract}
Background: RAD54L (OMIM 6036I5, Locus Link 8438) has been proposed as a candidate oncosupressor in tumours bearing a non-random deletion of Ip32, such as breast or colon carcinomas, lymphomas and meningiomas. In a search for RAD54L mutations in 29 menigiomas with allelic deletions in Ip, the only genetic change observed was a silent $\mathrm{C} / \mathrm{T}$ transition at nucleotide 2290 in exon 18. In this communication the possible association of the $2290 \mathrm{C} / \mathrm{T}$ polymorphism with the risk of meningiomas was examined. In addition, the usefulness of this polymorphism as a genetic marker within the meningioma consensus deletion region in Ip32 was also verified. The present study comprises 287 blood control samples and 70 meningiomas from Spain and Ecuador. Matched blood samples were only available from Spanish patients.
\end{abstract}

Results: The frequency of the rare allele- $T$ and heterozygotes for the $2290 \mathrm{C} / \mathrm{T}$ polymorphism in the blood of Spanish meningioma patients and in the Ecuadorian meningioma tumours was higher than in the control population $(P<0.05)$. Four other rare variants $(2290 \mathrm{C} / \mathrm{G}, 2299 \mathrm{C} / \mathrm{G}, 23 \mathrm{I} / 3 \mathrm{G} / \mathrm{A}$, $2344 \mathrm{~A} / \mathrm{G}$ ) were found within $50 \mathrm{bp}$ at the 3 ' end of RAD54L. Frequent loss of heterozygosity for the $2290 \mathrm{C} / \mathrm{T} \mathrm{SNP}$ in meningiomas allowed to further narrow the Ip32 consensus region of deletion in meningiomas to either $2.08 \mathrm{Mbp}$ - within DIS27I3 (44.35 Mbp) and RAD54L (46.43 Mbp) - or to I.47 Mbp - within RAD54L and DIS2I34 (47.90 Mbp) - according to recent gene mapping results.

Conclusion: The statistical analysis of genotypes at the $2290 \mathrm{C} / \mathrm{T}$ polymorphism suggest an association between the rare $T$ allele and the development of meningeal tumours. This polymorphism can be used as a genetic marker inside the consensus deletion region at Ip32 in meningiomas.

\section{Background}

Meningiomas are slow-growing tumours derived from the arachnoid membrane surrounding the central nervous system. They are one of the commonest intracranial tu- mours, accounting for $20 \%$ of all brain tumours, with an overall incidence of 2.3/100,000 and a 2:1 female-to-male ratio [1]. The frequent finding of asymptomatic meningiomas in computerised tomography and magnetic 
resonance studies [2] will probably raise these prevalence figures. A close relationship exists between meningiomas and neurofibromatosis type II (NF2). Meningiomas have been found in more than $50 \%$ of patients with this common hereditary disorder and sporadic meningiomas show frequent mutations in the NF2 oncosupressor gene [3-5]. Besides NF2, other candidate genes are suspected to be involved in the multistep development of meningiomas; among these genes are those presumably inactivated by deletion/mutation in 1p32, a region of frequent loss of heterozygosity (LOH) in sporadic and hereditary meningiomas [4,6-9]. Mapped at 1p32 and with likely functions in mitotic and meiotic recombination, RAD54L (OMIM 603615, Locus Link 8438), a member of the SNF2/SWI2 family of DNA-dependent ATPases, has been proposed as a candidate oncosupressor in breast tumours [10]. The finding of mutations in a small fraction of breast carcinomas ( 1 out of 95 tumours), colon carcinomas ( 1 out of 13 tumours) and lymphomas (1 out of 24) supports the involvement of RAD54L in tumorigenesis [11].

In a previous single strand conformation polymorphism (SSCP) analysis of 29 meningiomas with 1 p deletions we failed to detect any mutation in the RAD54 L gene, but found instead a silent $\mathrm{C} / \mathrm{T}$ polymorphism (Ala730Ala) that was identified by direct sequencing of PCR-amplified exons [12]. This polymorphism has been independently identified (NCB SNP cluster ID: rs1048771) in chromosome 1 contig NT_004386 using high output methods for SNP detection. Blast analysis has unequivocally linked the variation to nucleotide 2290 of RAD54L mRNA (Gen Bank accession X97795.1) or to nucleotide position 2851 in the NCBI RefSeq (accession NM_003579.2); however, lack of information regarding population genotype and allele frequency has precluded its validation as an SNP marker. In this communication the possible association of $2290 \mathrm{C} / \mathrm{T}$ polymorphism with the risk of meningiomas was examined. In addition, the usefulness of this polymorphism as a genetic marker within the meningioma consensus deletion region in 1 p32 [6] was also ascertained.

\section{Methods \\ Tissue samples}

Twenty-nine Spanish tumours with deletions in 1p and matched blood samples were obtained from meningioma patients as previously described [5,12]. Forty-one paraffin archival, randomly-chosen, samples of meningiomas (20 meningothelial, 11 transitional, 5 fibroblastic, 3 psamomatose and 2 angioblastic) were obtained from the pathology services of E. Espejo and C. Andrade Marín hospitals in Quito, Ecuador. Two of them were grade II and 39 grade I, according the WHO Classification. No matched blood samples from those patients were availa- ble. Spanish and Ecuadorian blood control were obtained from healthy transfusion blood donors.

\section{DNA extraction}

Genomic DNA was prepared from frozen tissues by standard methods previously described $[5,12]$. DNA from paraffin-embedded samples was extracted by standardised protocols [13]. DNA from peripheral lymphocytes was extracted using a DNA-extraction kit from Stratagene, according to the manufacturer's protocol.

\section{PCR based analysis of RAD54L polymorphism and Ip pol- ymorphic markers}

The allelic status of $2290 \mathrm{C} / \mathrm{T}$ polymorphism in tumour and blood samples was ascertained by PCR amplification of exon 18 followed by SSCP analysis as described [12]. On some occasions confirmatory direct sequencing analysis of PCR products was carried out as described [12]. The allelic status at microsatellite loci was analysed as described $[5,12]$.

\section{Statistical analysis}

Epidemiological variables and genotypes were evaluated using Tukey-Kramer comparison tests, Odds ratios and Fisher's two-sided exact test.

\section{Results and discussion}

In order to validate the SNP status of the $2290 \mathrm{C} / \mathrm{T}$ polymorphism we have extended our previous observations with the analysis of additional Spanish control population (up to 87 healthy blood donors) and have also included a new control group of 149 healthy blood donors and 41 menigioma samples from Ecuador. In Table 1 we summarise the epidemiological data of the patients included in this study. The sex ratio in both Ecuadorian and Spanish patients (2.7 and 3.1 female/male ratio, respectively) is higher than that reported for larger populations. The age at diagnostic is similar in the Ecuadorian sex groups and in the Spanish male patients, but is higher in the Spanish female group. Marked differences were also observed in tumour histopathology. While most of the Ecuadorian meningiomas were of WHO grade I, the Spanish tumours were of a predominant grade II-III histology. These dissimilarities originate from the selection criterion used in selecting meningioma patients - random in Ecuador, LOH for 1p markers in Spain - and the well established correlation between $1 \mathrm{p}$ loss and meningioma progression $[5,6]$.

As shown in Table 2, heterozygotes and T-allele frequencies were statistically indistinguishable in control population groups from Ecuador and. In both cases the results conform to the Hardy and Weinberg equation. We have also measured allele frequencies for the RAD54L $2290 \mathrm{C} /$ $\mathrm{T}$ polymorphism in meningioma patients from Spain and 
Table I: Stratification of menigioma patients by sex, age, grade, and histology

\begin{tabular}{|c|c|c|c|}
\hline Patients & Ecuador & Spain & $P$ values a (Ecuador vs. Spain) \\
\hline Total & 41 & 29 & \\
\hline \multicolumn{4}{|l|}{ Female } \\
\hline number & 30 & 22 & n.s. ${ }^{b}$ \\
\hline mean age (years) & 50.3 & 62.4 & $P<0.05$ \\
\hline \multicolumn{4}{|l|}{ Male } \\
\hline number & 11 & 7 & n.s. \\
\hline mean age (years) & 48.3 & 49.7 & n.s. \\
\hline \multicolumn{4}{|l|}{ Grade } \\
\hline I & 39 & 5 & $P<0.0001$ \\
\hline II-III & 2 & 21 & $P<0.0001$ \\
\hline \multicolumn{4}{|l|}{ Histology } \\
\hline meningotheliomatous & 20 & 11 & n.s. \\
\hline transitional & 11 & 6 & n.s. \\
\hline other & 10 & 4 & n.s. \\
\hline n.a.c & - & 3 & \\
\hline
\end{tabular}

a Tukey-Kramer Multiple Comparison Test for age and sex comparison. Fisher's Exact Test for grade and histology. b n.s., "not significant". c n.a," "not available".

Ecuador. The Spanish group included. 29 tumour samples with 22 matched peripheral blood samples from a subset of patients with LOH for at least one marker of chromosome 1p and prevailing atypical/anaplastic histology (see Table 1) as previously reported [5]. Heterozygosity and Tallele frequencies were higher in the lymphocyte DNA from Spanish patients $(\mathrm{P}=0.0036$ and 0.0037 , respectively) as compared with the Spanish control population. The heterozygosity in the Spanish meningeal tumours (0.069) was much lower than in the patient's peripheral blood (0.500) and in Ecuadorian tumours (0.732). This discrepancy is an expected consequence of the selection criterion for the Spanish meningioma (LOH for at least one marker of $1 p)$ and the frequent loss of heterozygosity ( $9 / 11$ informative cases, $82 \%$ ) observed for the $2290 \mathrm{C} / \mathrm{T}$ polymorphism in this tumour group. The frequency of the rare Tallele $(0.22)$ in the Spanish meningioma group is similar to the patient's blood and higher than in the healthy controls. Similar frequency has been reported in a mutational study of several tumour samples [11]. The meningeal tumours from Ecuador, consisting of 41 archival paraffin samples with a predominant WHO grade I histology (see Table 1) showed (Figure 1 and Table 2) a very high rate of heterozygosity, amounting to $73 \%$ of this group versus $20 \%$ in the control Ecuadorian population. Although the predominantly typical histology would suggest a low incidence of $1 p$ deletions $[5,6]$ in these tumour samples, the unavailability of blood from Ecuadorian patients prevented the ascertainment of $\mathrm{LOH}$ and hemizygosity in the tumour samples and, as a result, the frequency of the Callele was probably overestimated. Even with this drawback, the frequency of heterozygosis and T-alleles was very high and extremely significant when compared with the
Ecuadorian control population $(\mathrm{P}=0.0001)$. The similitude between Ecuadorian tumours and the constitutive Spanish patients genotypes, with higher heterozygosity and T-allele frequency than their healthy population controls are noteworthy, and suggest the presence of an association between the 2290T-allele and the development of meningeal tumours.

Besides the 2290C/T polymorphism, other rare variants were found at the 3 ' end of RAD54L exon 18, as summarised in Figure 2, together with the mismatches (boxes 1, 4 and 5 in the figure) between genomic and mRNA sequences already reported in the NCBI database (Evidence View, graphic display option) when searched for RAD54L. Besides the 2290C/T polymorphism, a new silent 2290C/ G variant (box 1-2 in Figure 2) has been found in 1 out of the 11 sequenced Ecuadorian meningeal tumours. Another new 2299C/G, F733L variant (box 3 in Figure 2) has been found with a low frequency $(1 / 11)$ in Ecuadorian tumours. The 2313G/A, R738H variant (box 4 in the figure 2 ) has already been reported as a mismatch. Finally, a new 2344A/G variation (box 6 in Figure 2) replaces the 747stop codon with a tryptophan and displaced the protein termination signal to the next TAA codon in position 748 . This variation has been found in the Ecuadorian $(1 / 11)$ and Spanish (1/13) samples. The high density of variations found in exon 18 ( 5 in 52 nucleotides) is noteworthy and suggests the occurrence of a genomic instability at the 3 ' end of RAD54L.

The high frequency of constitutional heterozygosity in the $2290 \mathrm{C} / \mathrm{T}$ alleles found in a subset of meningioma patients with deletions in the short arm of chromosome 1 (Table 


\section{$\begin{array}{lllllllllllllllllllll}1 & 2 & 3 & 4 & 5 & 6 & 7 & 8 & 9 & 10 & 11 & 12 & 13 & 14 & 15 & 16 & 17 & 18\end{array}$}

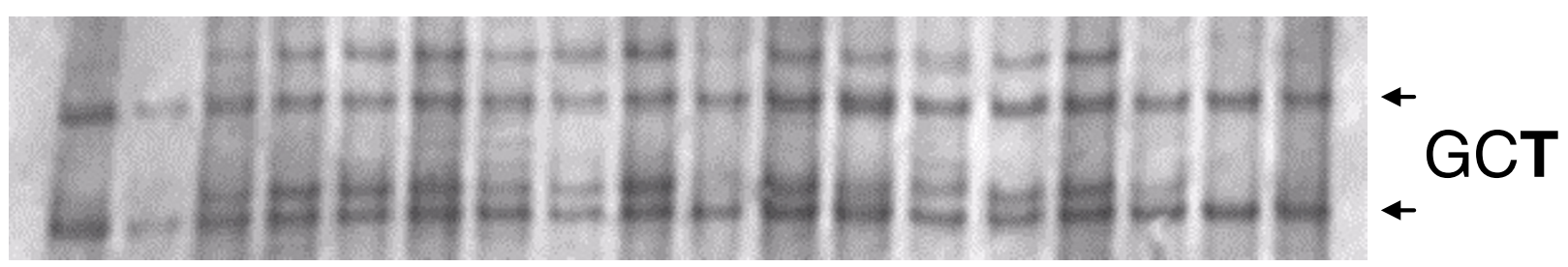

19202122232425262728293031323334353637

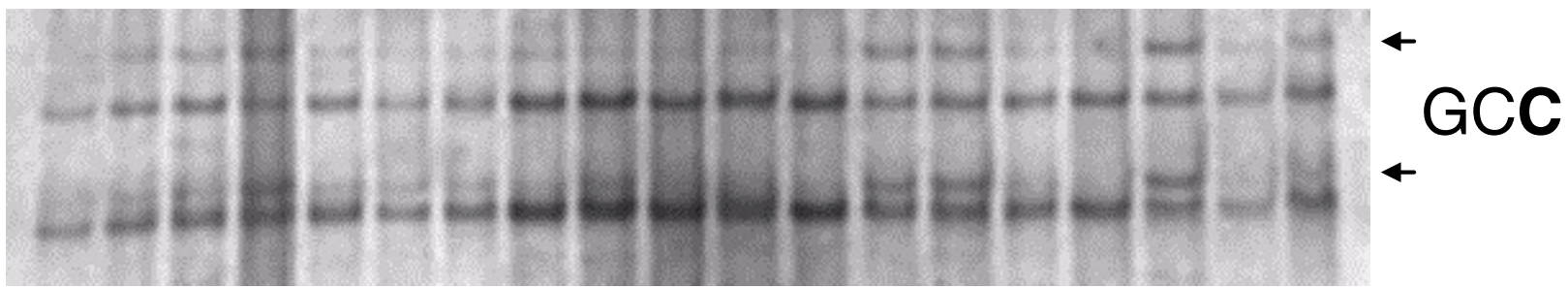

\section{Figure I}

Status of the 2290C/T polymorphism in meningiomas from Ecuador. DNA was extracted from paraffin archival and $2290 \mathrm{C} / \mathrm{T}$ alleles were characterised by PCR-SSCP as described in methods. The figure shows a representative SSCP of 37 cases. Arrowhead point to $\mathrm{T}$ and $\mathrm{C}$ alleles migration in the gel.

Table 2: Heterozygotes and T-allele frequencies in population controls and meningioma patients. Alleles were identified by exon 18 PCR amplification followed by SSCP as described [12].

\begin{tabular}{|c|c|c|c|c|}
\hline $\begin{array}{l}\text { Groups and number of patients or tumour } \\
\text { samples }\end{array}$ & $\begin{array}{l}\text { Heterozygosis } \\
\text { frequency }\end{array}$ & $\begin{array}{l}\text { Group comparison for heterozygotes } \\
\text { vs. homozygotes }{ }^{b}\end{array}$ & T-allele frequency ${ }^{c}$ & $\begin{array}{l}\text { Group comparison for T-allele } \\
\text { frequencyb }\end{array}$ \\
\hline A) Control blood from Ecuador $N=149$ & $29 / 149(0.195)$ & & $31 / 298(0.104)$ & \\
\hline B) Control blood from Spain N = 87 & $15 / 87(0.172)$ & $\begin{array}{l}\text { A-B) } O R=1.160(0.583-2.309) P= \\
0.7313\end{array}$ & $19 / 174(0.109)$ & $\begin{array}{l}\text { A-B) } O R=0.878(0.5175-1.734) P \\
=0.8776\end{array}$ \\
\hline C) Patients blood from Spaind $\mathrm{N}=22$ & $11 / 22(0.500)$ & $\begin{array}{l}C-B) O R=4.800(1.758-13.103) P= \\
0.0036\end{array}$ & I3/44 (0.295) & $\begin{array}{l}\text { C-B) } O R=3.421(1.531-7.646) P \\
=0.0037\end{array}$ \\
\hline D) Meningioma tumours from Spain d,e N = 29 & $2 / 29(0.069)$ & $\begin{array}{l}\text { D-B) } O R=0.355(0.076-1.660) P= \\
0.2327\end{array}$ & $1 \mathrm{I} / 49(0.224)$ & $\begin{array}{l}D-B) O R=2.357(1.081-5.140) P \\
=0.0455\end{array}$ \\
\hline E) Meningioma tumours from Ecuador ${ }^{f} \mathrm{~N}=4 \mathrm{I}$ & $30 / 41(0.732)$ & $\begin{array}{l}\mathrm{E}-\mathrm{A}) \mathrm{OR}=\mathrm{I} \mathrm{I} .285(5.064-25.148) \mathrm{P}< \\
0.000 \mathrm{I}\end{array}$ & $30 / 82(0.366)$ & $\begin{array}{l}E-A) O R=4.969(2.773-8.905) P \\
=0.000 \mathrm{I}\end{array}$ \\
\hline
\end{tabular}

\footnotetext{
a Number of heterozygotes / number of cases or tumour samples. Frequency in brackets. b Odds Ratio (OR) with $95 \%$ confidence values in brackets and $\mathrm{P}$ value (two-sided Fisher's exact test) $\mathrm{C}$ Number of T-alleles / total chromosomes in group. Frequency in brackets. $\mathrm{d}$ Patients selected for LOH in Ip markers in tumour samples. Blood was unavailable in 7 of the patients. Data revised from Mendiola et al. 1999 (ref. I2)e Number of chromosomes is reduced to 49 for LOH found in 9 samples. ${ }^{f}$ Archival paraffin samples as described in the methods. Hemizygosis was not evaluable due to lack of patients' blood.
} 


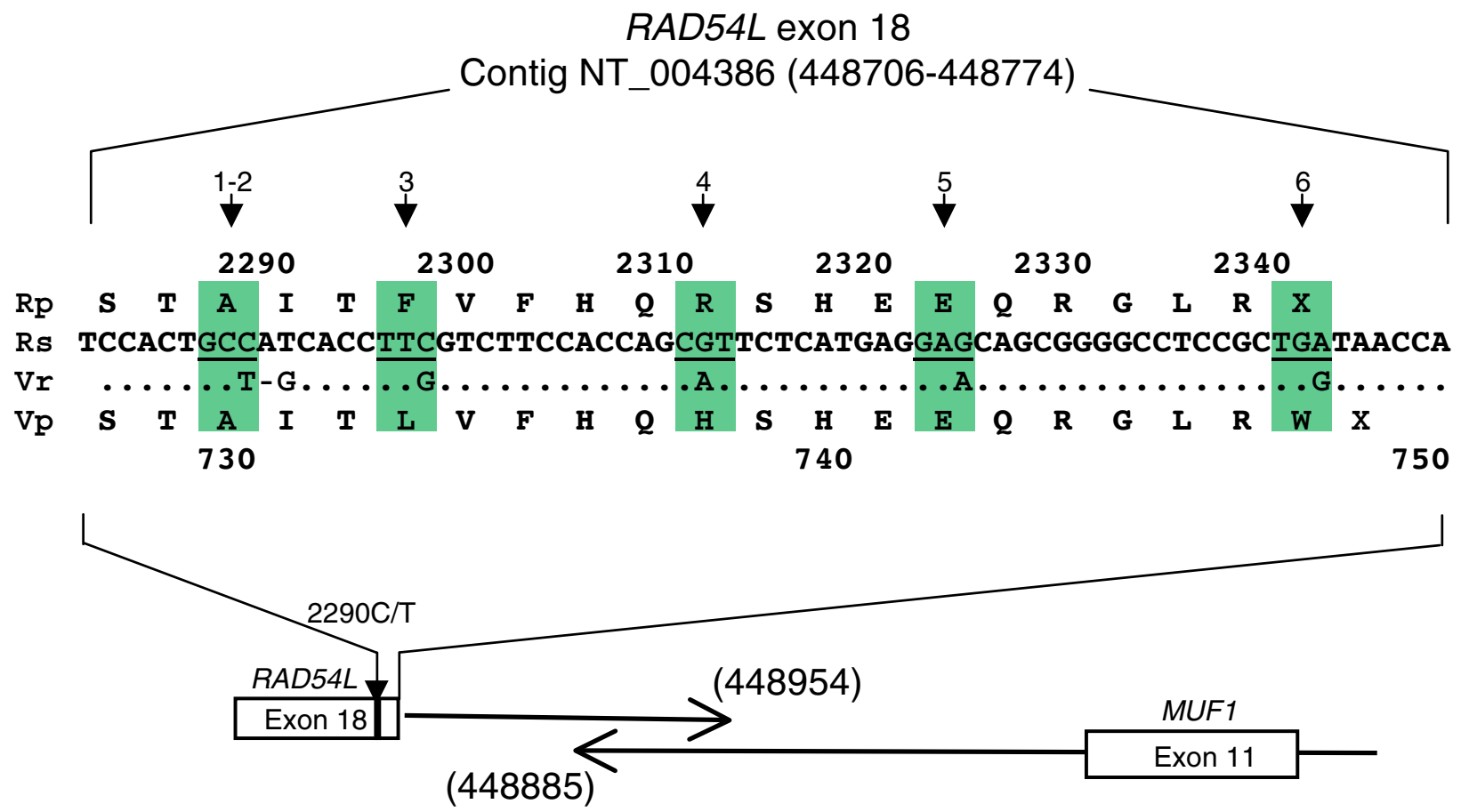

\section{Figure 2}

Variants and mismatches in exon 18 of RAD54L and molecular linkage of RAD54L and MUFI through an inverse overlapping of untranslated mRNA. In the upper side of the figure, variants found in meningiomas (numbered I-2, 3, 4, 5 and 6) and mismatches reported in the NCBI (Evidence Viewer, graphic display for RAD54L) (I, 4 and 5) are shown in bold within green boxes. The figure displays from top to bottom: the reference protein (Rp) and mRNA (Rs) at the $3^{\prime}$ end of RAD54L, the variants and mismatches $(\mathrm{Vr})$ and their corresponding protein sequences $(\mathrm{V} p)$. In the lower part of the figure the inverse overlapping 70 bp sequence shared by RAD54L and MUFI 3'UTR is shown. Figures in brackets correspond to nucleotide positions in the NT_004386 contig.

1) together with the frequent loss of heterozygosity for the $2290 \mathrm{C} / \mathrm{T}$ alleles in the Spanish meningeal tumours $(82 \%$ of the informative cases), suggests that this SNP could be used as a 1p32 marker inside the critical $1.5 \mathrm{cM}$ consensus deletion region in meningiomas [6]. Using our own published $[5,12]$ and unpublished (Mendiola. Chemistry MS thesis, UAM, Madrid, 1999) data, together with recent information on the sequence map for chromosome 1 (available through the web of the NCBI, Entrez Genome and UniSTS, updated as of September 2002), we were able to identify 2 tumour samples (numbers 13 and 14 in figure 3 ) in which the LOH for the 2290C/T SNP marker further reduced the $1 \mathrm{p} 32$ consensus region for deletion in meni- giomas (3.55 Mbp) within D1S2713 (44.35 Mpb) and D1S2134 (47.90 Mbp), to either the 2.08 Mbp between D1S2713 and RAD54L (46.43 Mpb) or the $1.47 \mathrm{Mbp}$ between RAD54L and D1S2134 (see Figure 3). This narrowed definition of the minimal region of allelic loss excludes candidate genes telomeric to D1S211 (44.07 Mbp), such as GROS1 [15], mapped at $43.3 \mathrm{Mbp}$, or genes centromeric to D1S197 (51,70 Mbp), such as CDKN2C [16]. The exclusion of CDKNC2 as a candidate oncosupressor in meningiomas has also been suggested in recent molecular studies [9]. TAL1 [17] and SIL [18], which map at $50.20 \mathrm{Mbp}$ within the consensus deletion region (Figure 3), have proto-oncogen functions in leukaemia, and 
A

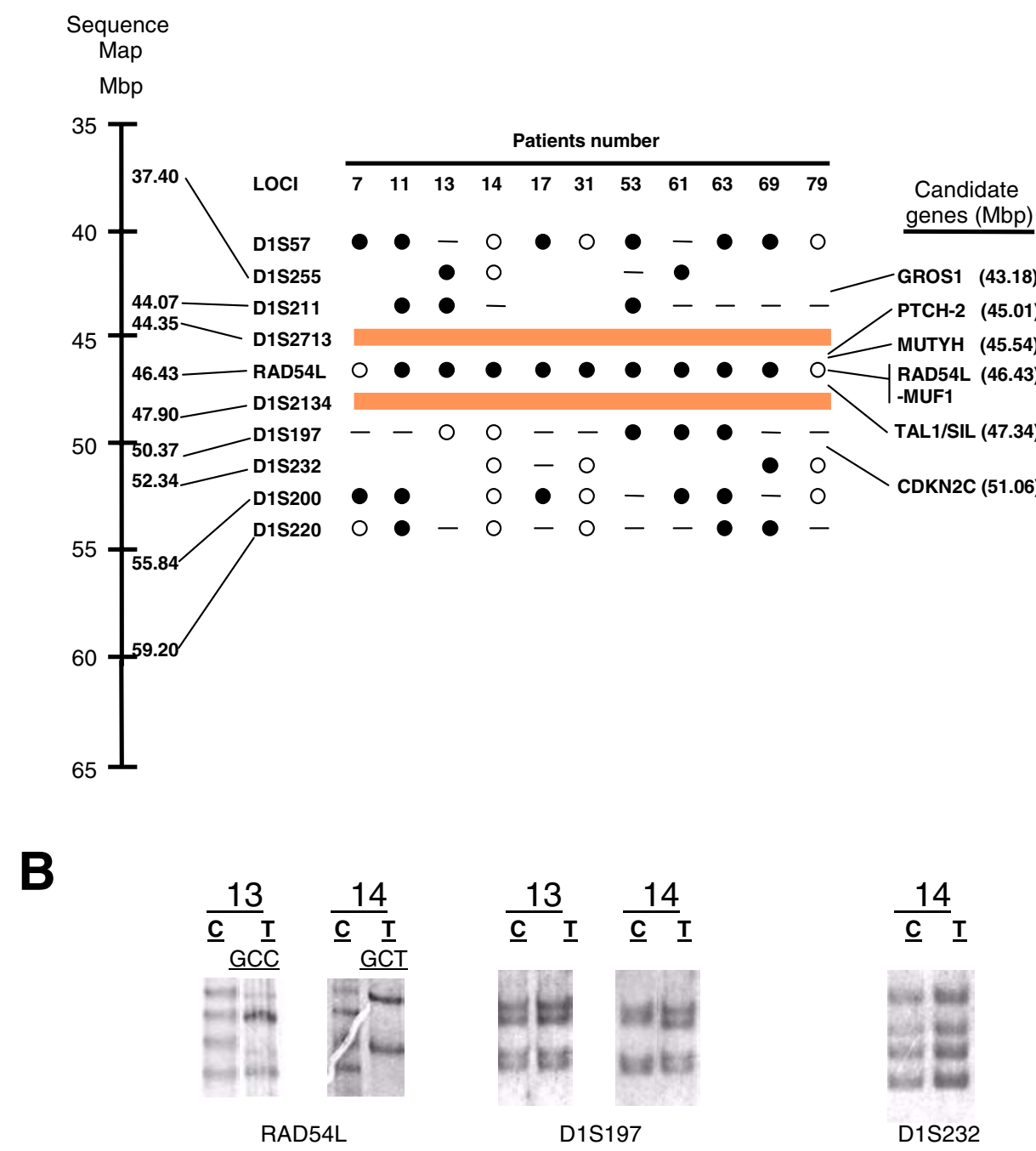

Figure 3

Summary of LOH analysis and map information. A. Sequence maps of Ip markers and genes were obtained from NCBI gene maps and UniSTS records (updated as of September 2002). Salmon coloured horizontal lines delimit the smallest overlapping region flanked by DIS27I3 and DIS2 I 34 [6]. LOH results for II RAD54L polymorphism informative cases are taken from previous published and unpublished results (see the text). Open and closed circles correspond to retention and loss of heterozygosity respectively. The horizontal bar represents uninformative constitutional homozygosis. Patient identification as in ref. 5. B. SSCP of constitutive (C) and tumoral (T) DNA from patients 13 and I4, showing LOH of RAD54L and retention of heterozygosity for DISI 97 and DIS232 markers. 
are unlikely oncosupressor candidates. Besides $R A D 54 L$, other oncosupressor candidates mapping within the smallest region of overlap (D1S2713-RAD54L) are PTCH2, MUTYH and MUF1. PTCH2 (OMIM 603673, Locus Link 8643), the human homologue of Drosophila patched-hedgehog, has been implicated in malignancies such as medulloblastoma and basal cell carcinoma [19]. MUTYH (OMIM 604933, Locus Link 4595), a homologue of the yeast mutY gene, is an oxidative mismatch repair protein [20] which could be involved with MUTL in susceptibility to hereditary nonpolyposis colon cancer (HNPCC, OMIM 120535). MUF1 (Locus Link 10489) has recently been characterised as an Elongin BC-interacting protein, akin to the Von Hippel Landau (VHL) tumour supressor protein in its ability to assemble with Cul5 and Rbx1 and reconstitute a ubiquitin ligase [21]. To our knowledge none of these putative candidate genes has been studied in meningiomas.

The statistical association between the rare $\mathrm{T}$ allele in the $2290 \mathrm{C} / \mathrm{T}$ polymorphism and the risk of meningioma development (Table 1 ) requires some attention. It is unlikely that the 2290C/T silent variation (Ala730Ala) could result in functionally different alleles, and there is no evidence for any plausible effect on mRNA transcription. Alternatively, it is possible that the T-allele is in linkage disequilibrium with another sequence of DNA directly implicated in tumour development. According to the draft chromosome 1 sequence (accession NT_004386, in Entrez Nucleotide from NCBI web), RAD $54 L$ and MUF1 share 69 bp of a convergent and inverted untranslated mRNA that contains the poly $(\mathrm{A}+)$ signal and the site for polyadenylation for both genes (Figure 2). This is a condition for dsRNA production that could initiate a chain reaction of gene silencing through degradation of homologous messenger RNA molecules [22,23]. Whether the 2290T-allele is actually linked to a gene silencing mechanism through homologous antisense dsRNA of either the RAD54L mRNA or MUF1 mRNA would require dilucidation in further studies, which also have to consider the genomic instability observed at the 3 ' end of RAD54L.

\section{Conclusions}

The statistical analysis of genotype (2290C/T) distribution among meningioma patients and healthy controls suggests that the rare $\mathrm{T}$ allele is associated with the risk of meningioma development. In addition, this study also shows that the $2290 \mathrm{C} / \mathrm{T}$ variation can succesfully be exploited as a polymorphic marker inside the consensus deletion at $1 \mathrm{p} 32$ in meningiomas.

\section{List of abbreviations}

PCR (polymerase chain reaction), SSCP (single stranded chain polymorfism), LOH (loss of heterozygosity), SNP (single nucleotide polymorphism)

\section{Competing interests}

None declared.

\section{Authors' contributions}

PEL and CPM processed and analyzed tissue and blood samples from Ecuador. MM and JA processed the Spanish samples. AP coordinated the study and drafted the manuscript.

\section{Web links}

Entrez http://www.ncbi.nlm.nih.gov/Entrez is the NCBI common retrieval system for SNP, UniSTS, OMIM, nucleotide, genome and other databases.

LocusLink http://www.ncbi.nlm.nih.gov/LocusLink is the NCBI iterface for search curated sequences and information about genetic loci.

\section{Acknowledgements}

This work was supported by grants from the Spanish Ministry of Education and Science (Programa de Cooperación Científica con lberoamérica). MM is a fellow from the Spanish Ministry of Health (Fondo de Investigación Sanitaria). We are indebted to Paola Nebreda and Javier Pérez for able technical assistance in processing tissue specimens and drawings,

respectively. The careful reading of the manuscript by Brenda Ashley is also acknowledged.

\section{References}

I. Bondy $M$ and Lignon BL Epidemiology and etiology of intracranial meningiomas: a review. J Neurooncol 1996, 29:197-205

2. Kuratsu J, Kochi $M$ and Ushio $Y$ Incidence and clinical features of asymptomatic meningiomas. J Neurosurg 2000, 92:766-770

3. Harada T, Irving RM, Xuereb JH, Barton DE, Hardy DG, Moffat DA and Maher ER Molecular genetic investigation of the neurofibromatosis type 2 tumor suppressor gene in sporadic meningioma. J Neurosurg 1996, 84:847-85।

4. Lamszus K, Vahldiek F, Mautner VF, Schichor C, Tonn J, Stavron D, Fillbrandt, Westphal $M$ and Kluwe $L$ Allelic loses in neurofibromatosis 2-associated meningiomas. J Neuropathol Exp Neurol 2000, 59:504-512

5. Leone PE, Bello MJ, de Campos JM, Vaquero J, Sarasa JL, Pestaña A and Rey JA NF2 mutations and allelic status of Ip, I 4q and 22q in sporadic meningiomas. Oncogene 1999, I 8:2231-2239

6. Sulman EP, Dumanski JP, White PS, Khao H, Maris JM, Mathiesen T, Bruder C, Cnaan A and Brodeur GM Identification of a consistent region of allelic loss on Ip32 in meningiomas: correlation with increased morbidity. Cancer Res 1998, 58:3226-3230

7. Carlson KM, Bruder C, Nordenskjöld M and Dumanski JP I p and 3p deletions in meningiomas without detectable aberrations of chromosoma 22 identified by comparative genomic hybridization. Genes Chromosomes Cancer 1997, 20:4 19-424

8. Lindblom A, Ruttledge M, Collins VP, Nordenskjöld M and Dumanski JP Chromosomal deletion in anaplastic meningiomas suggest multiple regions outside chromosome 22 as important in tumor progression. Int J Cancer 1994, 56:354-357

9. Leuraud P, Marie Y, Robin E, Huguet S, He J, Mokhtari K, Cornu P, Hoang-Xuan $K$ and Sanson M Frequent loss of I 32 region but no mutation of the pl8 tumor suppressor gene in meningioma. J Neurooncol 2000, 50:207-213 
10. Rasio D, Murakum Y, Robbins D, Roth T, Silver A, Negrini M, Schmidt C, Burczak J, Fishel R and Croce CM Characterization of the human homologue of RAD54: a gene located on chromosome Ip32 at a region of high loss of heterozygosity in breast tumors. Cancer Res 1997, 57:2378-2383

II. Matsuda M, Miyagawa K, Takahashi M, Fukuda T, Kataoka T, Asahara $\mathrm{T}$, Inui H, Watatani M, Yasutomi M, Kamada N, Dohi K and Kamiya K Mutations in the RAD54 recombination gene in primary cancers. Oncogene 1999, I8:3427-3430

12. Mendiola M, Bello MJ, Alonso J, Leone PE, Vaquero J, Sarasa JL, Kusak ME, de Campos JM, Pestaña A and Rey JA Search for mutations of the hRAD54 gene in sporadic meningiomas with deletion at Ip32. Molecular Carcinogenesis 1999, 24:300-304

13. Herrington CS and McGee OD Diagnostic Molecular Pathology: A Practical Approach. The Practical Approach Series. Oxford, IRL Press 1992, 93-94

14. Kanaar R, Toelstra C, SMA, Swagemakers Essers J, Smit B, Franssen $\mathrm{JH}$, Pastink A, Bezzubova OY, Buerstedde JM, Clever B, Heyer WD and Hoeijmakers HJ Human and mouse homologs of the Saccharomyces cerevisiae RAD54 DNA repair gene: evidence for functional conservation. Curr Biol 1996, 6:828-838

15. Kaul SC, Sugihara T, Yoshida A, Nomura H and Wahwa R GrosI, a potential grwth suppresor on chromosome I: its identity to basement membrane-associated proteoglycan, leprecan. Oncogene 2000, 19:3576-3583

16. Blais A, Labrie $Y$, Pouliot $F$, Lachance $Y$ and Labrie $C$ Structure of the gene encoding the human cyclin-dependent kinase inhibitor p 18 and mutational analysis in breast cancer. Biochem Biophys Res Commun 1998, 247:146-153

17. Begley CG, Visvader J, Green AR, Aplan PD, Metcalf D, Kirsch IR and Gough NM Molecular cloning and chromosomal localization of the murine homolog of the human helix-loop-helix gene SCL. Proc Natl Acad Sci USA 1991, 88:869-873

18. Aplan PD, Jones CA, Chervinsky DS, Zhao X, Ellsworth M, Wu C, McGuire EA and Gross KW An scl gene product lacking the transactivation domain induces bony abnormalities and cooperates with LMOI to generate T-cell malignancies in transgenic mice. EMBO J 1997, 16:2408-24I9

19. Smyth I, Narang MA, Evans T, Heimann C, Nakamura Y, ChenevixTrench G, Pietsch T, Wicking $C$ and Wainwright BJ Isolation and characterization of human patched $2(\mathrm{PTCH} 2)$, a putative tumour suppressor gene in basal cell carcinoma and medulloblastoma on chromosome Ip32. Hum Mol Genet I999, 8:29I297

20. Slupska MM, Baikalov C, Luther WM, Chiang JH, Wei $\mathrm{P}$ and Miller $\mathrm{H}$ Cloning and sequencing a human homolog (hMYH) of the Escherichia coli mut $Y$ gene whose function is required for the repais of oxidative DNA damage. J Bacteriol 1996, I78:38853892

21. Kamura T, Burian D, Yan Q, Schmidt SL, Lane WS, Querido E, Branton PE, Shilatifard A, Conaway RC and Conaway JW Mufl, a novel Elongin BC-interacting leucine-rich repeat protein that can assemble with Cul5 and $\mathrm{RbxI}$ to reconstitute a ubiquitin ligase. J Biol Chem 200I, 276:29748-29753

22. Carthew RW Gene silencing by double-stranded RNA. Curr Opin Cell Biology 200I, 13:244-248

23. Nishikura K A short primer on RNAi: RNA-directed RNA polymerase acts as a key catalist. Cell 200I, 107:415-4I8

\section{Pre-publication history}

The pre-publication history for this paper can be accessed here:

http://www.biomedcentral.com/1471-2407/3/6/prepub

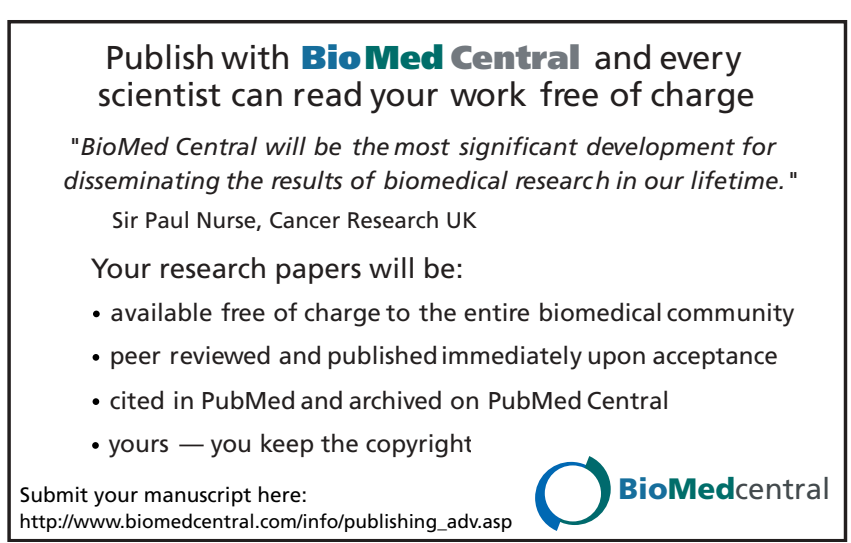

